\author{
EVS29 Symposium \\ Montréal, Québec, Canada, June 19-22, 2016
}

\title{
The Development of Hybrid and Electric Vehicles: Emergence and Development of the Patent Network
}

\author{
Thomas Crispeels ${ }^{1}$, Dimitri Robert ${ }^{1}$, Wouter Verbeke ${ }^{1}$, Thierry Coosemans ${ }^{1} \&$ Joeri Van Mierlo ${ }^{1}$ \\ ${ }^{1}$ Vrije Universiteit Brussel, Pleinlaan 2, 1050 Brussels, Thomas.Crispeels@vub.ac.be
}

\begin{abstract}
Summary
In this paper, we investigate the global R\&D network that emerged from EV and HEV technology development by firms and universities from 1998 to 2010. We visualize and analyze the development of the relevant (joint) patent network and uncover some of the key R\&D dynamics within the automotive industry, such as the evolution of the R\&D network over time, open innovation dynamics and university-industry collaborations. We use traditional network analytics and find that the R\&D network initially became less interconnected. In recent years, we see the network tightening again and being controlled by the large OEMs, this suggests that the move towards open innovation is relative and that technologies and markets are maturing. At the same time, the network became more international and universities start being part of the network. The findings of this paper allow for assessing the relative position of each company in EV and HEV R\&D network, as a result we can uncover the powerful organizations in the networks: those networks that control the knowledge generated by and flowing through the industry. The database developed within the framework of this research allows for developing an optimal network strategy both for incumbents or new entrants such as start-ups or universities.
\end{abstract}

Keywords: R\&D, innovation, Japan, EV, HEV

\section{Introduction}

The development and commercialization of EV and HEV (Electric and Hybrid Electric Vehicles) is a process that involves many stakeholders: automotive manufacturers (OEM), universities, SMEs and governments closely collaborate to determine the future of our global mobility and transportation [1] [2] [3]. During the $R \& D$ and commercialization processes of $(\mathrm{H}) \mathrm{EVs}$, no single organization possesses sufficient knowledge to successfully develop and commercialize such vehicles completely on its own. As a result, organizations active in the automotive industry engage in strategic alliances or inter-organizational collaborations, both in the field of R\&D and commercialization, a dynamic we witness in many other industries. Inter-organizational collaborations allow organizations to look for useful knowledge, technologies and innovation outside of the 
firm's boundaries [4]. As a result, many stakeholders in the industry interlock and a network of relationships between the organizations emerges. In this paper, we want to study the process of network formation and evolution in the EV and HEV R\&D domain in order to uncover how new technologies are developed and how an industry's network evolves when a technology matures. For this, we will scrutinize the joint patent applications of organizations developing HEV and EV technology. A joint patent application is the result of a joint R\&D effort. As such, we can use this patent data to reconstruct and analyze the industry's R\&D network at a given point in time or over a period of time. Based on our dataset, we investigate the evolution of the EV and HEV R\&D network from 2000 to 2010, a time period coinciding with an increased interest in EVs and HEVs and with their acceptance on the marketplace. Uncovering the R\&D network within the automotive industry allows for uncovering some of the key R\&D dynamics within the EV and HEV industry. Of notable interest are the following questions: Will the R\&D network in the automotive industry become more networked over time, or will we witness the emergence of different competing clusters or 'small worlds' of organizations that perform joint R\&D with few links to other organizations? Our analysis also allows for uncovering powerful nodes in the network, i.e. organizations that are structurally embedded in the network in such a way that they control the knowledge flowing through the R\&D network. These organizations possess a network position that allows them to access knowledge more quickly and more easily than their competitors whilst at the same time control information and knowledge flows, making them crucial players in the future of $(\mathrm{H}) \mathrm{EV}$. In summary, this paper will address the following research questions: (1) How did the R\&D network in the automotive (EV and HEV) industry evolve?; (2) Which are the central and powerful organizations in the EV and HEV R\&D network?; and (3) How easy can knowledge flow between networked organizations and within the R\&D Network? Previous studies highlight that the performance of firms is explained in part by its relative position with regard to its external environment [5]. By answering the previously stated research questions we want to scrutinize how networks evolve over time and how organizations build, maintain or lose their network position, which is crucial for their performance.

\section{Literature Review}

Production requires the application of multiple types of knowledge. Knowledge is considered to be one of the most important resources of a firm and many authors conclude that the principal role of the firm is as an integrator of knowledge. [6] [7] [8] Useful knowledge can be generated within the firm but can also be found outside of the firm's boundaries. In recent years, we witness an increase in the formation of alliances and R\&D collaborations as a formal vehicle to generate new knowledge or to access the counterpart's relevant knowledge. This spurred the general trend towards open innovation, where companies collaborate with universities, companies, government, customers and/or suppliers during product development and/or commercialization. The open innovation trend is further accelerated by the trend of firms focusing on their core competencies and by the fact that the knowledge and technology base are increasingly complex and exponentially expanding. Learning and innovation will thus occur both inside and outside the firm's boundaries [4][7][8][9]. As a result, access to external knowledge and the integration of this external knowledge into the organization is key to the organization's long-term competitive advantage and success. The better firms become in the absorption of external knowledge, the better the firm performs.

In the management literature, there is a lot of debate on how knowledge builds and spreads through an industry and how $R \& D$ collaborations emerge and evolve [7] [10] [11]. In order to contribute to this discussion, we study a crucial consequence of the open innovation trend: inter-organizational networks. As a result of multiple collaborations in domains such as commercialization, marketing and/or R\&D, organizations become embedded in inter-organizational networks. These networks represent the position of organizations in their environment and are formed by formal and informal links between different organizations. In particular, firms that are a member of networks have enhanced access to resources, most notably to knowledge, and are aware of opportunities that are not accessible to organizations outside of the network [12]. Since the early 2000s, network studies receive substantially more attention in management science [13]. 
Strong inter-organizational networks, sometimes referred to as 'small worlds', lead to a higher level of networked firm innovativeness as strong inter-organizational networks allow for more effective knowledge transfer among the networked organizations, for the existence of knowledge spillovers within the network and for the sharing of resources [14] [15]. Furthermore, inter-organizational networks are also considered to be a source of trust, power and control. Network position of an organization can also serve as a signalling mechanism, i.e. a strong network position can send signals of quality or performance to external stakeholders. As a result, and not surprisingly, variance in organizational performance is best explained by a combination of both the organization's internal capabilities and its networking activities [5]. In other words, the stronger an organization's position in the relevant networks, the better its performance.

In our analysis, we focus on how the R\&D networks on HEV and EV technologies emerge and evolve within the automotive industry. We want to uncover the most important actors in this network and highlight how firms in the automotive industry position themselves in a network in order to generate or access new knowledge. Our analysis and data allows for assessing the role of universities within this industry and to see how the role of OEM car manufacturers evolved in the first decade of the $21^{\text {st }}$ century.

In order to uncover the R\&D network in the automotive industry we turn to patent applications, which allow us to uncover the patent network. The patent network is the inter-organizational network that emerges when organizations jointly apply for a patent. A patent is an exclusive right that gives the patent owner or licensee the right to make, sell or exploit an invention during a certain period of time. Organizations will engage in joint patenting (also called co-patenting) when they want to formally protect the results of joint scientific and technological efforts and investments and when no contractual agreements have been made [10][16]. When a joint patent application is filed, this typically means that the applicant organizations have finished a project during which they have exchanged scientific and technological knowledge and staff members. Figure 1 shows the basic layout of a patent network emerging from joint patent applications. The organizations are represented by circles and referred to as nodes. The nodes in this network are linked to each other by joint patent applications, represented by edges.

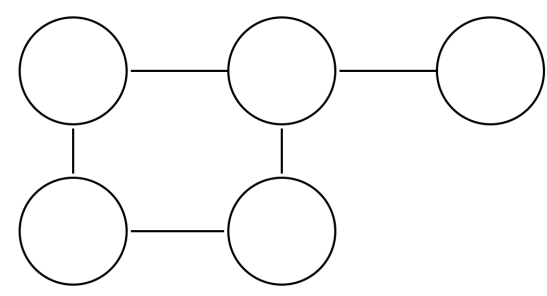

Figure 1: Example of a patent network.

Patent networks have been extensively analysed in (innovation) management literature and are scrutinized at the level of individual inventors, inventor teams or applicant organizations. Inter-organizational patent networks are mainly analysed in light of uncovering knowledge transfer dynamics [16][17]. For instance, Cassiman, Veugelers and Zuniga et al. [18] find that firms with scientific collaborations perform better than organizations with no scientific linkages and patents from companies with strong links to the science community appear to have a larger impact than 'solo' patents. With regard to the heterogeneity characterizing high-technology industries, Balconi et al. [10] find that academic inventors play a more central role in the patent network than their non-academic peers. This means that academic inventors act as important information brokers and play an important role in bringing together research teams from different institutions or companies. 


\section{Data}

In order to construct the EV and HEV patent network we obtained access to the European Patent Office's Global Patent Index Database. We downloaded all patent applications from the worldwide patent catalogue within those IPC classes identified by the IPC Committee of Experts as containing patents on 'Green Vehicles' (Green Technology Inventory, category 'Transportation' ${ }^{1}$ ). This approach allows us also to include complementary technology developments (e.g. batteries in other applications) impacting EV and HEV development in our analysis. Our final database consists of 327,928 Patent Applications and covers a broad range of technology domains including, but not limited to, control systems, batteries, motors, control systems, regenerative braking systems, etc. All patent applications were downloaded on December 12, 2014. Since publication of a patent application can take up to 18 months or even longer, for the analysis we only consider patent applications until December 31, 2010 in order to be sure all relevant patent applications are included.

For each patent application in our database we listed application date, patent applicants and the individual inventors. In a first step, we filtered out duplicates, patents with a missing application date and patent family members. Patent family members are patent applications covering the same invention as the representative patent application, but in different countries or jurisdictions. These family members are thus also a type of duplicates. After this filtering, we retained 14,579 patent applications between the years 1900 and 2010 in our database. We decided to limit our research focus to the period 2000-2010 as this period is characterized by the emergence of the HEV and EV market following the introduction of the Toyota Prius in 1997. Next, we selected the 'joint' patent applications, i.e. patent applications with more than one applicant. Subsequently we attributed each patent to the relevant co-applicant organizations using several databases: Google Patents, Justia Patents, Patent Scope and Google Scholar. In most cases, this meant that individual inventors (which are typically also listed as applicants) had to be attributed to an organization such as a company or a university. For US patents, organizations cannot be listed as applicants on the original patent application, so we retrieved the applicant organizations by looking at the relevant legal documents and inventor affiliations for the relevant period.

When we look at the patent application activity during this period (Figure 2 and Table 1), we immediately see a number of interesting things. The number of patent applications has exploded since 2008: in 2010 there are almost five times more patent applications than in 2007. It is worth noting that 2007 was the only year since 1998 when the number of patent applications dropped compared to the year before. Interestingly, the number of joint patent applications is low and is relatively stable over time. As a result, its relative importance has sharply decreased over the last years.

${ }^{1}$ http://www.wipo.int/classifications/ipc/en/est/ 


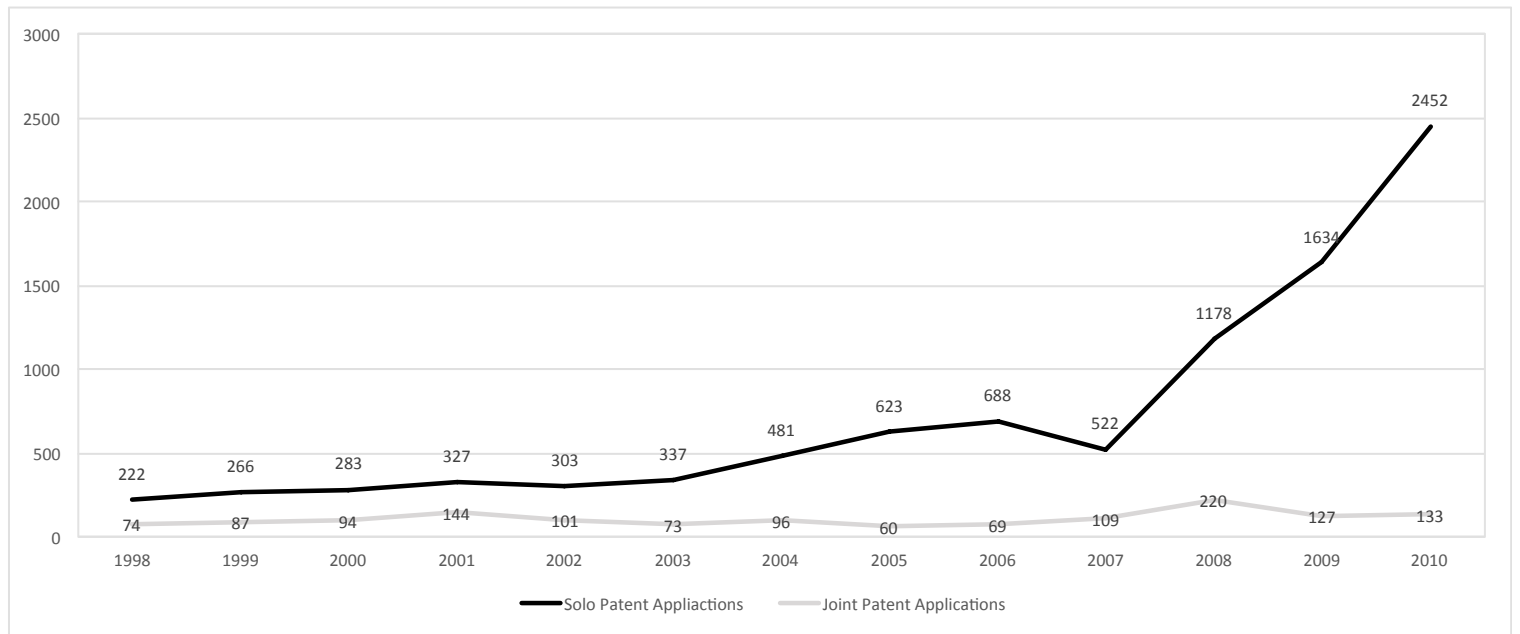

Figure 2: Number of Solo and Joint Patent Applications in EV and HEV Technologies (1998-2010).

Table 1: Descriptive Statistics of Patent Applications in EV and HEV Technologies (1998-2010).

\begin{tabular}{lccc}
\hline & All PAs & Joint PAs & Solo PAs \\
\hline Mean & 823,31 & 106.69 & 716.62 \\
Std. Dev. & 683,37 & 42.66 & 662.80 \\
Median & 577 & 96 & 481 \\
$\mathrm{~N}$ & 10,703 & 1,387 & 9,316 \\
\hline
\end{tabular}

Based on our final dataset, we are now able to construct the patent networks where organizations (companies and research institutions) are the nodes and joint patent applications form the edges for each year. Obviously, a joint patent application is the result of a preceding $R \& D$ collaboration that often spans more than a single year. During this entire collaboration period preceding the patent application, knowledge is exchanged and generated. Therefore, we consider that for each joint patent we found, collaboration already existed during the two years preceding the patent application. This means that, for instance, the R\&D network in 2000 consists of connections between organizations based on the patent applications of 2000, 2001 and 2002. We acknowledge that this is an arbitrary cut-off point, future research will allow us to vary this time period and get a more nuanced image on the robustness of our findings. For further analysis in this paper, we selected three points in time for which we will construct and analyze the joint patenting network: 2000, 2004 and 2008 (see Figure $3)$.

\section{Methodology}

We apply network analysis methods to uncover the properties of the joint patent network in order to answer three key questions: (1) How did the R\&D network in the automotive (EV and HEV) industry evolve?; (2) Which are the central and powerful organizations in the EV and HEV R\&D network?; and (3) How easy can knowledge flow between networked organizations and within the R\&D Network [19][20]?

In order to identify key players in the relevant network and to investigate the strength of network players, we look at a number of network characteristics in our weighted, undirected network.

To uncover the relative power of the network nodes (firms and universities), we use three measures as introduced by Freeman [19]. First, networks are characterized by the presence of hubs. These hubs are organizations in a network that are connected to many other actors through joint patent applications. As a 
result, hubs have a central role in the diffusion of information and knowledge within the network [21]. For each organization in our network, we calculate the Degree centrality. Degree centrality measures the number of ties that connect a node to other network actors. A high degree centrality indicates the extent to which an organization can act as a hub in the network.

Second, we consider the distance between a node and all other nodes within the network. If the distance of a node to all other nodes is short, a short chain of acquaintances links the organization to all other nodes in the network. In order to measure this, we calculate each node's Closeness centrality, which measures the distance, i.e. the number of edges separating a node from all other nodes of the network. The higher a node scores on this measure, the shorter its relative distance to all other nodes and the more easy and rapid the node can access knowledge flowing through the network.

Third, we consider the position of the node in the network relative to other nodes. Indeed, the more central a node (i.e. in between other nodes in the network), the higher the degree of control over the information flow in the network this node possesses. For this, we use the Betweenness centrality measure, which quantifies how many times a node is part of the shortest path between all the pairs of nodes within the network.

These centrality measures describe the position of the individual organizations within the network but still fail to capture network dynamics that serve to answer our research questions with regard to the network as a whole. Therefore, we complement Freeman's centrality measures with measures that tell us something about the full network: the average clustering coefficient and the average path length. The clustering coefficient measures to what extent nodes form tightly knit groups characterized by a relatively high density of links between nodes [22]. The average path length is the average distance or number of steps there are between all node pairs within the network.

It is important to note that all measures are calculated for the Largest Connected Component (LCC) in the network, i.e. the network component with the largest number of nodes, for each of the uncovered networks. This also allows us to calculate all measures since measures such as path length between two unconnected nodes can not be calculated. Importantly, we see more or less the same LCC emerging in the network, so we can compare measures over time. The measures are normalized in order to allow comparison between the different networks over the time periods. For the normalized degree centrality, the degree is divided by the number of nodes minus one. The closeness centrality is multiplied with this value in order to have a normalized result. For the betweenness centrality, we use the formula described by Freeman [19].

\section{Results and Discussion}

Figure 3 depicts the uncovered R\&D networks in 2000, 2004 and 2008. The circles are the nodes in our network and represent the applicant organizations of the joint patent applications in our database: firms and universities. The size of circles represents the weighted degree (which is also called the strength) of the node and indicates the total amount of edges of a node. The darker a node, the higher its betweenness centrality. Green nodes represent universities. The connection lines between nodes are edges. In our case, an edge represents a patent application linking two nodes in our network with each other. The thickness of the edges is representing the number of patent applications two organizations share.

On Figure 3, one may immediately observe that the network consists of a number of independent (unconnected) components, but is dominated by a largest connected component (LCC) in all three periods. This LCC can be called the 'Japanese Component'. Most companies in this component are Japanese companies and include all major OEMs and a considerable amount of component manufacturers. This is not surprising, as the Japanese economy is characterized by Keiretsu's: strong vertically integrated networks of companies surrounding large corporations (such as car manufacturers) [23]. At the same time, Japanese OEMs 
were always at the forefront of electrification meaning that it is logic to find the largest network here. This is further supported by the fact that multiple US and EU based OEMs are present in the 2008 network.

(1) How did the R\&D network in the automotive (EV and HEV) industry evolve?

In order to answer this research question we look at the evolution of the LCC network characteristics over the first decade of the 21 st century (

Table 2). We observe that the number of nodes (firms and universities) as well as the number of edges (joint patent applications) in the R\&D network decrease steadily over time. This means that knowledge about EV and HEV technology is developed and shared by an increasingly limited amount of organizations. At the same time, we observe that the average path length first increases (from 2000 to 2004) and then decreases (from 2004 to 2008). The clustering coefficient makes the inverse motion, with clustering first decreasing and then increasing again in the last period. These observations lead us to conclude that during the first period, there occurred disintegration or widening of the R\&D network studied. Indeed, organizations were on average more distant from each other and relatively few 'small worlds' within the network existed, although fewer organizations were member of the network. In the second half of the first decade of the $21^{\text {st }}$ century, we then witness a clear tightening of the relevant R\&D network. In light of the explosion of the number of patent applications on EV and HEV technologies, this points out that the 'Green Car' industry is maturing and EV and HEV technologies are becoming mainstream. When an industry grows, there is a 'shake out' dynamic during which the number of firms active in the industry declines due to M\&A activity or bankruptcies. Further research should clarify whether the R\&D network architecture is 'tightening' due to such a shake out dynamic and that mature industries boast a very dense and interlinked R\&D network compared to young industries. Our findings are even more interesting when we take into account the fact that the network studied has become more international (GM, BMW, Daimler, Chrysler...) and thus a widening of the network could be expected.

Table 2: LCC Characteristics, 2000, 2004 an 2008.

\begin{tabular}{lccc}
\hline R\&D Network & $\mathbf{2 0 0 0}$ & $\mathbf{2 0 0 4}$ & $\mathbf{2 0 0 8}$ \\
\hline Nr. Of Nodes & 109 & 97 & 65 \\
Nr. Of Edges & 161 & 123 & 82 \\
Avg. Path Length & 3.57 & 4.60 & 3.21 \\
Avg. Clustering Coefficient & 0.57 & 0.49 & 0.62 \\
\hline
\end{tabular}




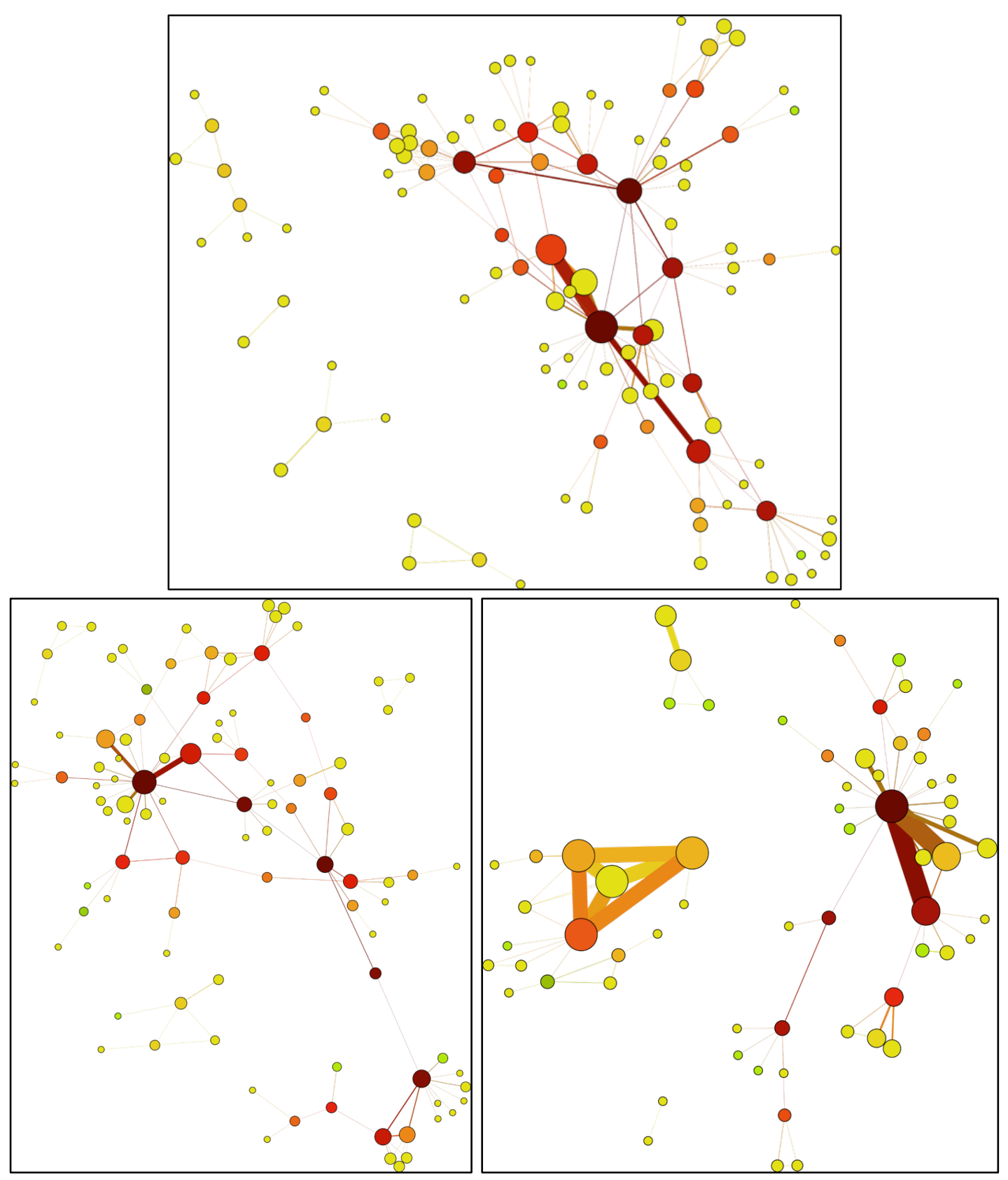

Figure 3: EV and HEV R\&D Network, 2000 (top), 2004 (bottom left) and 2008 (bottom right)

(2) Which are the central and powerful organizations in the EV and HEV R\&D network?

Table 3, Table 4 and Table 5 depict the normalized centrality measures for the R\&D network in 2000, 2004 and 2008 respectively. We can immediately see that Toyota is by far the most central and powerful organization in the R\&D network throughout the entire period studied. This means that Toyota, due to its strong position in this network, is extremely well placed to access new knowledge and opportunities arising in the EV and HEV domain. Over time, we see that they develop very strong connections with Aisin (in which they are a minority shareholder) and Denso Corporation (of which they are by far the largest customers). An sich, this is not very surprising, but what is interesting is that both organizations, over time, evolve into powerful and central nodes in the R\&D network. Thus, organizations that link up with powerful and central 
nodes (in this case Toyota) can quickly achieve a strong position in the network. This has important implications for organizations wishing to gain such a powerful position and will influence their partnering strategy. We can also observe this when universities enter the R\&D network. These organizations do not possess a lot of ties to the network but succeed in immediately achieving a strong position in the network. The fact that they can do this in a clearly "industry driven" domain such as EV and HEV suggests that universities possess strong networking capabilities, something already proven in other "university driven" industries such as the biotechnology industry [24]. Other Japanese OEMs are also well represented in the network studied, and over time, we also see the emergence and embedding of international OEMs such as GM, BMW, Daimler... Interestingly, these international players are immediately occupying strong positions in the network. As noted above, it is interesting to see that although the network becomes more international, it also becomes smaller and tighter.

Of note are also the strong network positions of large diversified Japanese industrial players and major component suppliers such as Hitachi, Sumitomo and Toshiba. We can also clearly see a crucial role in the R\&D network for Japanese Gas and Electric Power companies in the 2000 R\&D network. These companies gradually disappear from the network and by 2008 they are completely absent. This further supports the 'maturation' assumption from research question (1), companies from surrounding domains engage and experiment in a new and promising domain (EV and HEV). In this case, the radical innovation of the car concept towards HEV and EV has sustained the position of traditional OEMs and did not give rise to a major disruption in the automotive industry.

(3) How easy can knowledge flow between networked organizations and within the R\&D Network?

The observation of relatively short distances and high clustering leads us to conclude that the R\&D network studied is conducive to knowledge transfer. The network, however, is characterized by a small amount of very powerful organizations. As such, we conclude that the characteristics of this network favor these powerful organizations in the industry (OEMs and their close partners) and thus would sustain the competitive advantage of the incumbents on the market rather than to provide opportunities for new entrants. The fact that Keiretsu's characterize the Japanese industry of course hinders new entrants and competitors from joining the network. New organizations entering the network with the aim of benefiting from the knowledge flowing through the network would need enhanced network building capabilities. Indeed, we have also seen that the knowledge is more easily accessed by organizations that are close to the OEMs with regard to their core competencies, e.g., suppliers, daughter companies, or that possess a certain scale, such as large industrial players. The few universities that are part of the network succeed in reaching a powerful position and thus can tap into the relevant knowledge. SMEs are gradually shaken out of the knowledge-sharing network.

Table 3: Top 15 networked organizations based on normalized centrality measures, 2000

\begin{tabular}{lrlrlr}
\hline Node & Degree & Node & Betw & Node & Close \\
\hline TOYOTA & 0.176 & TOYOTA & 0.343 & TOYOTA & 0.045 \\
NISSAN & 0.139 & SUMITOMO & 0.224 & SUMITOMO & 0.045 \\
MITSUBISHI & 0.130 & NISSAN & 0.218 & HITACHI & 0.045 \\
HITACHI & 0.093 & HITACHI & 0.193 & FUJI & 0.044 \\
HONDA & 0.093 & HONDA & 0.163 & TOKYO GAS & 0.044 \\
KANSAI ELEC PWR & 0.083 & FUJI & 0.156 & NISSAN & 0.044 \\
TOHOKU & 0.083 & TOKYO GAS & 0.152 & SHIN KOBE ELEC MACH & 0.044 \\
OSAKA GAS & 0.074 & JAPAN STORAGE BATT & 0.105 & DAIHATSU & 0.044 \\
SHIKOKU & 0.074 & TOSHIBA & 0.101 & FDK & 0.044 \\
TOKYO GAS & 0.074 & MITSUBISHI & 0.085 & HIOKI ELEC WORKS & 0.044 \\
CHUBU ELEC PWR & 0.065 & TOHOKU & 0.071 & KOJIMA PRESS KOGYO & 0.044 \\
CHUGOKU ELEC PWR & 0.065 & TAIHEIYO KOGYO & 0.067 & TOKAI RIKA & 0.044 \\
FUJI & 0.065 & SHIN KOBE ELEC MACH & 0.066 & TOYODA GOSEI & 0.044 \\
HOKURIKU ELEC PWR & 0.065 & DENSO & 0.062 & UNIV KYOTO & 0.044 \\
OKINAWA ELEC PWR & 0.065 & OSAKA GAS & 0.054 & JAPAN STORAGE BATT & 0.043 \\
\hline
\end{tabular}


Table 4: Top 15 networked organizations based on normalized centrality measures, 2004

\begin{tabular}{lrlrll}
\hline Node & Degree & Node & Betw & Node & Close \\
\hline TOYOTA & 0.208 & TOYOTA & 0.399 & HONDA & 0.052 \\
MITSUBISHI & 0.104 & HITACHI & 0.367 & TOYOTA & 0.052 \\
HONDA & 0.083 & HONDA & 0.282 & HITACHI & 0.052 \\
MEIDEN & 0.083 & MITSUBISHI & 0.266 & SEIKO & 0.050 \\
HITACHI & 0.073 & SHIN KOBE ELEC MACH & 0.257 & ORIGIN ELEC & 0.050 \\
OSAKA GAS & 0.063 & MEIDEN & 0.094 & FUJIMORI KOGYO & 0.050 \\
AISIN & 0.052 & AISIN & 0.087 & NIPPON DENGI KK & 0.050 \\
FURUKAWA & 0.052 & SEIKO & 0.087 & ASANO GEAR & 0.050 \\
JAPAN RES INST & 0.052 & OSAKA GAS & 0.086 & CHUO MOTOR WHEEL & 0.050 \\
NISSAN & 0.052 & NISSAN & 0.085 & EBARA & 0.050 \\
TOHO GAS KK & 0.052 & FUJI & 0.077 & KEIHIN & 0.050 \\
TOSHIBA & 0.052 & FURUKAWA & 0.070 & MABUCHI MOTOR & 0.050 \\
DAIMLERCHRYSLER & 0.042 & MITSUI & 0.070 & TI WALBRO JAPAN & 0.050 \\
DENSO & 0.042 & NTN CORP & 0.062 & TOKAI RIKA & 0.050 \\
FUJI & 0.042 & SUZUKI MOTOR & 0.061 & AISIN & 0.049 \\
\hline
\end{tabular}

Table 5: Top 15 networked organizations based on normalized centrality measures, 2008

\begin{tabular}{lrlrll}
\hline Node & Degree & Node & Betw & Node & Close \\
\hline TOYOTA & 0.297 & TOYOTA & 0.357 & TOYOTA & 0.036 \\
GM & 0.125 & AISAN & 0.169 & MITSUBISHI & 0.035 \\
AISIN & 0.109 & DENSO & 0.163 & HONDA & 0.035 \\
NISSAN & 0.094 & MITSUBISHI & 0.151 & FURUKAWA & 0.035 \\
CHRYSLER & 0.078 & AISIN & 0.146 & SUMITOMO & 0.035 \\
DAIMLER & 0.078 & NISSAN & 0.130 & CHUBU GIKEN & 0.035 \\
HONDA & 0.078 & HONDA & 0.083 & FUJ & 0.035 \\
BMW & 0.063 & ERICSSON & 0.058 & NAT UNIV YOKOHAMA & 0.035 \\
DENSO & 0.063 & HITACHI & 0.040 & TOYODA GOSEI & 0.035 \\
ERICSSON & 0.063 & GM & 0.036 & TOSHIBA & 0.035 \\
FURUKAWA & 0.063 & IAV AUTOMOTIVE ENG & 0.032 & YAZAKI & 0.035 \\
IAV AUTOMOTIVE ENG & 0.063 & FURUKAWA & 0.026 & MITSUBA & 0.035 \\
UNIV SHANGHAI JIAOTONG & 0.063 & UNIV SHANGHAI JIAOTONG & 0.023 & CSIRO & 0.034 \\
YAZAKI & 0.063 & MITSUBA & 0.020 & TOKAI RIKA & 0.034 \\
BOSCH & 0.047 & TOKAI RIKA & 0.020 & DAIHATSU & 0.034 \\
\hline
\end{tabular}

\section{Conclusion and Implications}

In this paper, we investigate the global R\&D network that emerged from EV and HEV technology development by firms and universities from 2000 to 2010. We visualize and analyze the development of the relevant (joint) patent network and answer the following research questions: (1) How did the R\&D network in the automotive (EV and HEV) industry evolve?; (2) Which are the central and powerful organizations in the EV and HEV R\&D network?; and (3) How easy can knowledge flow between networked organizations and within the R\&D Network? We find that the R\&D network studied is conducive to knowledge transfer yet is characterized by a small amount of very powerful organizations. We conclude that the characteristics of this network evolve in such a way that they favor OEMs and their close partners. As such the network becomes a closed network and knowledge is shared between a few large companies. This means that accessing the R\&D network, which should give competitive advantage to a firm, by new entrants is very hard and hampers disruption of the industry from an R\&D perspective. In order to validate our findings, in a next study, the major assumption that a joint patent is the result of a two-year collaboration will have to be verified. 
The scope of our research and the methodology applied limits the findings of this study: network research complements the resource-based view of the firm, which explains firm performance focusing on individual firm characteristics and capabilities. In order to have a full view on the variance in organizational performance and its evolution, we should turn to studying a combination of the organization's internal capabilities and its network characteristics [5]. This concerns an avenue for future research.

As such, we uncover reasons for engaging in collaborative R\&D with universities and highlight how Green Car firms access relevant third party knowledge. We control for regional differences in R\&D networks and possible learning effects occurring in the network. Further research should include other R\&D networks and will allow for strategic R\&D management tool development. Such a tool would assist industry stakeholders in partner selection and/or competitive analysis. Adding technical content from the patent applications (patent classes, technologies, claim content) would further expand and strengthen this tool. The tool envisioned allows companies (incumbents or new entrants) to devise a strategy to become embedded in the industry's R\&D network. Indeed, when companies will engage in collaborative R\&D, a good and well-thought partner selection can make that the organization can access a lot more knowledge by linking up with a central node in the network. And better access to knowledge leads to better performance.

\section{Bibliography}

[1] P. Van Den Bossche et al., Evolutions in Hydrogen and Fuel Cell Standardization: The HarmonHy Experience, World Electric Vehicle Journal, 1(2007), 148-154.

[2] P. Van Den Bossche et al., Matching Accessories: Standardization Development in Electric Vehicle Infrastructure, World Electric Vehicle Journal, 4(2011), 921-926.

[3] S. Ili et al., Open innovation in the automotive industry, R\&d Management, 40(2010), 246-255.

[4] M. A. Hitt, et al., Technological learning, knowledge management, firm growth and performance: an introductory essay. Journal of Engineering and Technology Management, 17(2000), 231-246.

[5] A. Zaheer et al., It's the connections: The network perspective in interorganizational research, The Academy of Management Perspectives, 24(2010), 62-77.

[6] B. Kogut \& U. Zander, Knowledge of the firm, combinative capabilities, and the replication of technology, Organization science, 3(1992), 383-397.

[7] R. M. Grant, Toward a knowledge-based theory of the firm, Strategic management journal, 17(1996), 109122.

[8] R. M. Grant \& C. Baden-Fuller, A knowledge accessing theory of strategic alliances, Journal of management studies, 41(2004), 61-84.

[9] W. M. Cohen \& D. A. Levinthal, Absorptive capacity: A new perspective on learning and innovation, Administrative Science Quarterly, 35(1990), 128-152.

[10] M. Balconi et al., Networks of inventors and the role of academia: an exploration of Italian patent data, Research Policy, 33(2004), 127-145.

[11] C. Goetze, An empirical enquiry into co-patent networks and their stars: The case of cardiac pacemaker technology, Technovation, 30(2010), 436-446.

[12] R. Gulati, Network location and learning: The influence of network resources and firm capabilities on alliance formation, Strategic Management Journal, 20(1999), 397-420.

[13] B. Uzzi et al., Small-world networks and management science research: a review, European Management Review, 4(2007), 77-91.

[14] G. Ahuja, Collaboration networks, structural holes, and innovation: A longitudinal study, Administrative Science Quarterly, 45(2000), 425-455.

[15] M. A. Schilling \& C. C. Phelps, Interfirm collaboration networks: The impact of large-scale network structure on firm innovation, Management Science, 53(2007), 1113-1126.

[16] R. Belderbos et al., Co-ownership of intellectual property: Exploring the value-appropriation and valuecreation implications of co-patenting with different partners, Research Policy, 43(2014), 841-852. 
[17] X. Li et al., Patent citation network in nanotechnology (1976-2004), Journal of Nanoparticle Research, 9(2007), 337-352.

[18] B. Cassiman et al., Diversity of science linkages: A survey of innovation performance effects and some evidence from Flemish firms, Economics: The Open-Access, Open-Assessment E-Journal, 4(2010).

[19] L.C. Freeman, Centrality in social networks conceptual clarification, Social Networks, 1(1979), 215-239.

[20] R.A. Hanneman \& M. Riddle. Introduction to social network methods, 2005.

[21] E. Giuliani \& M. Bell, The micro-determinants of meso-level learning and innovation: evidence from a Chilean wine cluster, Research Policy, 34(2005), 47-68.

[22] D. J. Watts \& S. H. Strogatz, Collective dynamics of smallworld networks, Nature, 393(1998), 440-442.

[23] F. Bierau et al., Global Opportunities for SMEs in Electro-Mobility: Mapping of the e-mobility supply chain of electric mobility in Japan, GO4SEM Deliverable, 2015

[24] T. Crispeels et al., The relationship between organizational characteristics and membership of a biotechnology industry board-of-directors-network, Journal of Business \& Industrial Marketing, 30(2015), 312-323.

\section{Authors}

Prof. dr. Thomas Crispeels is Assistant Professor at the Vrije Universiteit Brussel at the department of Business Technology and Operations (BUTO). His research is situated in the field of Technology \& Innovation, with a special focus on technology transfer and collaborative R\&D in high technology industries such as the biotechnology and smart logistics industries. Thomas teaches several courses on technology entrepreneurship and the business economics of hightechnology industries to business and engineering students.

Dimitri Robert holds a MSc in Business Engineering and is Research Associate at the Vrije Universiteit Brussel at the department of Business Technology and Operations (BUTO). His research is situated in the field of complex network analytics and its ICT applications.

Prof. dr. Wouter Verbeke is an assistant professor in Data Analytics at Vrije Universiteit Brussel. His research is situated in the field of data mining, predictive analytics and complex network analysis, and is driven by real-life business problems that require a data driven solution, including applications in marketing, finance, as well as transport and mobility. Wouter teaches several courses on information systems and advanced modeling for decision making to business students, and has tutored several courses on credit risk modeling and customer analytics to business professionals.

Prof. dr. ir. Thierry Coosemans obtained his PhD in Engineering Sciences from Ghent University in 2006. After several years in the industry, he now became a member of the MOBI research team on transport technology at the VUB, where he works as a scientific project developer and project manager. He is an active member of EARPA and is involved in the current FP7 projects SafeDrive, OPERA4FEV, SuperLIB, Unplugged and Smart EV-VC as well as in the EVA, iMOVE, Olympus and EV-TecLab platforms of the Living Labs Electric Vehicles in Flanders. His main research interest are electric and hybrid propulsion systems.

Prof. dr. ir. Joeri Van Mierlo is a full-time professor at the Vrije Universiteit Brussel, where he leads the Mobility, Logistics and automotive technology research centre. Prof. Van Mierlo was visiting professor at Chalmers University of Technology, Sweden (2012). He is expert in the field of Electric and Hybrid vehicles (batteries, power converters, energy management simulations) as well as to the environmental and economic comparison of vehicles with different drive trains and fuels (LCA, TCO). He is IEEE Senior Member and authored more than 400 scientific publications. He is editor in chief of the World Electric Vehicle Journal and co-editor of the Journal of Asian Electric Vehicles and member of the editorial board of "Studies in Science and Technology" and of "ISRN Automotive Engineering". 